\title{
A Study on Impact Of Subjective Norms On Entrepreneurial Intention Among The Business Students In Bangalore
}

\author{
J.Krithika ${ }^{1}$, Dr.B.Venkatachalam ${ }^{2}$ \\ ${ }^{1}$ (Research scholar, Bharathiar University, Coimbatore, India) \\ ${ }^{2}$ (Research guide, $R \& D$ centre, Bharathiar University, Coimbatore, India)
}

\begin{abstract}
The impact of subjective norms on entrepreneurial Intention has not been uniform across the globe. GEM (global entrepreneurship monitor)conducted survey among the population aged 18 to 64 with 3000 as a sample size in India and found $22.7 \%$ of them got entrepreneurial Intention. This research investigates the relationship between the subjective norms and its impact on entrepreneurial Intention among 100 business students in Bangalore. The 100 respondents were selected based on the stratified random sampling. The result says that there is a significant relationship between the subjective norms and entrepreneurial intention among the business students in Bangalore.
\end{abstract}

Key words: Entrepreneurship, subjective norms, Entrepreneurial Intention.

\section{Introduction}

Entrepreneurship has emerged over the last couple of decade as possibly the strongest economic force that world has ever witnessed. The main reason forthis concern is the growing need for entrepreneur who accelerates economic development bygenerating new ideas and converting them in to profitable venture. Entrepreneurship has captured the attention of both scholars and policy makers during last decades. Entrepreneurial activities are not only the incubators of technological innovation; they provide employment opportunity and increase competitiveness also. Entrepreneurship is increasingly recognised as an important generator of growth, innovation and especially on new job creation.

Hence this paper deals with the impact of subjective norms on entrepreneurial careerintention among the business students in Bangalore.

\section{Subjective Norms And Career Intention}

In recent years, Theory of planned behaviour of Azjen has become one of the most widely used psychological theories to explain and predict human behaviour. The theory of planned behaviour illuminated the process of human action by linking it to three variables namely the Attitude towards behaviour (ATB), Subjective Norms (SN) and the Perceived behavioural control (PBC).

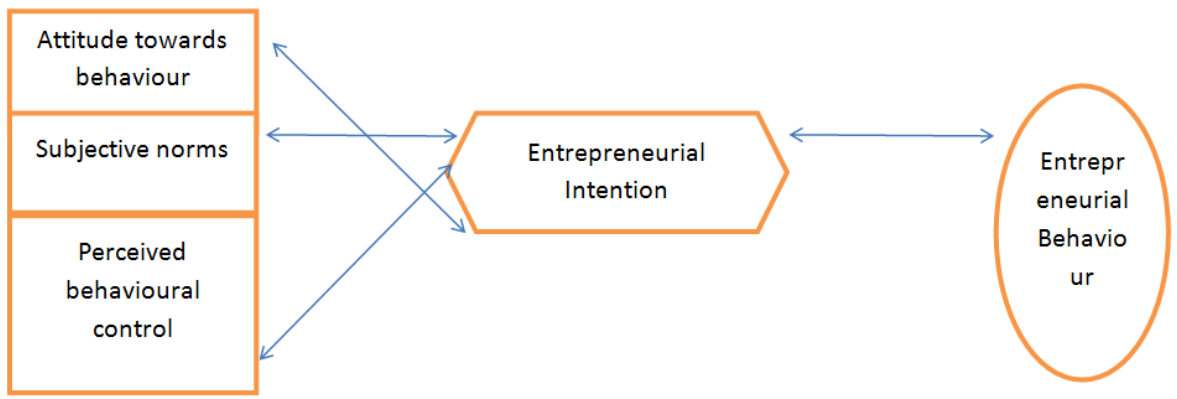

Attitude towards behaviour - The variable ATB refers to the degree to which a person has a favourable or unfavourable evaluation or appraisal of the behaviour. ATB refers one's personal attraction towards specific target behaviour.

Subjective norms - It refers to the perceived social pressure to perform or not to perform the behaviour which includes the influence of family, friends and other possible role models.

Perceived Behavioural control - The perceived controllability of the individual, and not the actual or realistic control has a certain threshold to be reached in the process of human action.

According to Azjen theory of Planned Behaviour, intentions are considered the best predictor of planned behaviour. Entrepreneurship is exactly the type of behaviour where intentions are necessary, useful for understanding and anticipating future development. In the TPB, these three variables precede the formation of intention as a predictor of behaviour. 
In the families, where the parents are entrepreneurs, theybecome role models for their children and youngsters. Theygain more respect from their wards as they are more experienced and who have given in their best for well being of their young. All important matters are discussed in family as they work together to achieve their business goal.Parent's success in running the family business makes the younger generation feel entrepreneurship as an attractive career choice.

The more supportive the subjective norms, the intention will be higher. If the target behaviour is more attractive to the individual, the intention will be higher. The people around the entrepreneur think thatthis individual should perform the target behaviour. This perceived social pressure to take, or not to take entrepreneurship as career, is one of the variables that precede the decision, said to be subjective norm.

\section{Objectives Of The Study}

The purpose of the study is to investigate whether subjective norms affects the entrepreneurial Intention and to examine the role of family background towards entrepreneurial intention.

\section{Discussions}

Shaperoargued that Intention towards entrepreneurship depend on exogenous factors like demographics, traits, skills, culture and social and financial support. Prior exposure to entrepreneurial activity would be included as one such factor. Prior exposure could be in the form of early exposure to a family business, which influences intentions towards entrepreneurial. This research found that those who reported a positive view of this family's business experiencing a high entrepreneurial Intention.

\section{Methods And Measures}

Data were collected from the primary source by using a well structured questionnaire. The sample size of the study was 100 students fromManagement colleges in Bangalore. Stratified sampling technique was adopted for this study. From colleges located in north Bangalore, south Bangalore, east Bangalore and west Bangalore, the respondents were selected. From every strata 25 students were selected for this research purpose. Parental self employment was measured by asking a question about whether their father owns his business? To check the influence of subjective norms on entrepreneurial Intention these questions were asked, ie. Their value on the perceptionof theclosest family members towardsself-employment, their value on the perception of their close friends towards self-employment and their value on the perceptionof somebody who is important towards self-employment. Apart from these four questions, five questions were asked related to self employment. The five questions were on having challenging work, desire to be their own boss, having power to make decisions, creating new and being engaged on the whole business. One direct question was asked to check about their entrepreneurial intention "How likely is it that you will choose career as a self employed entrepreneur?"

\section{Results And Discussions}

Out of 100 respondents, $34 \%$ o gave more value for the perception of closest family, $33 \%$ of them give more value for the perception of closest friendsand the closest people and people on their self employment behaviour.

The mean score value for entrepreneurial Intentions and subjective norms are as follows

\begin{tabular}{|l|l|}
\hline \multicolumn{1}{|c|}{ Variable and item } & Mean score \\
\hline Entrepreneurial Intention & \\
( 1 - Very likely to be employed & \\
2 - Likely to be employed & \\
3 - Likely to be self employed & 2.91 \\
4 - very likely to be self employed) & \\
\hline Attitude towards entrepreneurship & 3.50 \\
Having challenging work & 3.37 \\
Own boss & 3.23 \\
Power to make own decisions & 2.45 \\
Creating new - feels proud & 2.16 \\
Being engaged in whole business & \\
\hline Subjective Norms & 2.86 \\
Value on the perception of their closest family & \\
member towards self-employment & 2.84 \\
Value on the perception of their close friends & \\
towards self-employment & 2.84 \\
Value on the perception of important somebody \\
towards self-employment
\end{tabular}


Table represents the results of mean score for the variable mentioned. The overall tendency towards entrepreneurial career intention is very positive. With regards to the occupation of father only $37 \%$ of the respondent's fathers were self employed and entrepreneurs. While checking about the attitude towards their own entrepreneurial activity, the mean score for having challenging works is about 3.50, indicating the strong reasons for being an entrepreneur. While discussing on subjective norms, the mean score for their value on the perception of closet family towards their self-employment is found to have the highest mean $($ Mean $=2.86)$, which reveals that the respondents place high value on closest family's perception on their entrepreneurial activity.

The hypothesis formed for this study purpose was there is a strong relationship exists between the subjective norms and the entrepreneurial Intention.

\begin{tabular}{|l|c|c|c|c|}
\hline & Strong Intention & Moderate Intention & No Intention & Total \\
\hline Influence of subjective norms & 12 & 16 & 0 & 28 \\
\hline No Influence of subjective norms & 47 & 25 & 0 & 72 \\
\hline Total & 59 & 41 & 0 & 100 \\
\hline
\end{tabular}

(Source: Primary data)

Here the calculated value of chi square is 5.163 and the table value at 5\% level of significance is 5.991 . Hence the stated hypothesis is acceptable. Hence there is a strong relationship between the subjective norms and the entrepreneurial intentions.

Here we can observe that the business students in Bangalore give more value on the perception of their closest friends, family members. In general the subjective norms influence exists among the respondents. The perception from closest family that the respondents give more value is supported by Ajzen's (1998) study where such perception would reinforce the respondent's likelihood of becoming self employed. Some other studies also observed that family plays a significant role in career choice. ( Bohmer\&sitton 1993, deivasenapathey 1986). Nelson and shapero and sokels supporting the other two items ie., give more value to the perception of closest friends and perception from people that are important towards their self employment. Shapero feels that family, friends are considered as the key influencing individuals on influencing whether or not a person decides to start a new business venture.

\section{Conclusion}

This study found that family background and subjective norms play a major role and influence on entrepreneurial intention among the business students in Bangalore.

\section{References}

[1]. Ajzen. I (1998), Attitudes, Personality and Behaviour, Milton Kenynes, U.K Open University Press.

[2]. Ajzen. I (1991), The theory of planned behaviour, organisational behaviour and human decision process,Pg 179 -211.

[3]. Bohmer. P and Sitton.S (1993), The influence of birth order and family size on notable American women's selection of career, psychological record, Pg $375-38$.

[4]. Deivasenapathy.P (1986), Entrepreneurial success: Influence of certain personal variable, Indian journal of social work, Pg 547 555.

[5]. Nelson G.W (1989), Factors of friendship: relevance of significant other to family business owners, Entrepreneurship theory and practice, pg $7-8$.

[6]. ShaperoA (1975), Entrepreneurship and economic development, Wisconsin: ISEEDltd.

[7]. Kruger. N (1993), The impact of prior exposure to entrepreneurship on perceived new venture feasibility, desirability, Entrepreneurship theory and practice, pg $5-21$.

[8]. Global Entrepreneurship Monitor (GEM) - India Report, 2012 Pg 37 